\title{
Opinião
}

\section{RESILIÊNCIA COMO RECURSO PARA A SAÚDE EMOCIONAL}

O presente artigo trata sobre a resiliência. Trata-se de um construto que, apesar de não muito divulgado para a comunidade, tem sido objeto de estudo de especialistas das mais diversas áreas do conhecimento.

Muitas dificuldades e situações aterradoras tem marcado a humanidade, nas últimas décadas e, consequentemente afetado a vida de muitas pessoas. Mortes precoces por acidentes, guerras, abusos sexuais, crimes hediondos, separações conjugais e familiares, dentre outras. Apesar disso, muitos desses indivíduos conseguiram refazer as suas vidas e seguir em suas atividades cotidianas, ao invés de tomarem caminhos como o álcool, drogas, medicações entorpecentes, ficarem se lamentando inertes, ou até tomarem decisões drásticas como tirar a própria vida.

Estes indivíduos são conhecidos como resilientes, dada a sua capacidade de reagir a essas adversidades de uma maneira positiva e atuante.

A Resiliência é um termo empregado nas áreas de engenharia e física que o definem como a capacidade de um corpo físico resistir a uma determinada pressão, voltando ao seu estado anterior, sem alterar suas características originais (GALIETA, 2007). Nas áreas humanas e da saúde, este conceito foi re-significado, passando a ser compreendido como a capacidade que o indivíduo tem de, ao passar por situação dolorosa, ser capaz de retomar sua vida e suas atividades sem seqüelas mais graves. Essas pessoas conseguem raciocinar mais objetivamente, mesmo sob forte pressão, buscando soluções para suas dificuldades.

Esses indivíduos tem sido alvo de empresas, que estão preferindo contratar e conservar funcionários que saibam lidar com pressões e frustrações sem se deixarem abater. São empresas que evitam em seus quadros de recursos humanos, pessoas que se lamentam ou que se abatem rapidamente frente às dificuldades. Este comportamento, além de contagioso, 
torna-se nocivo na empresa em tempos de grande competitividade, como atualmente (MONTEIRO, 2001).

Dessa forma, pessoas que conseguem atravessar obstáculos de forma flexível, sem perder a cabeça, que valorizam o bom humor, o otimismo e a confiança, são observados de maneira mais positiva pelas organizações.

O resiliente dentro de uma empresa não se deixa abater, não desiste, está sempre em busca de novas soluções procurando entender onde errou e acertar da próxima vez.

Resilientes tendem mais a buscarem no auto-conhecimento, o equilíbrio necessário para aprenderem a transformar emoções negativas em positivas. Afirmam que o trabalho voluntário é um ótimo aprendizado na medida que observam pessoas em situações piores que as suas e, mesmo assim, ainda são capazes de sorrir.

Entretanto, para que haja resiliência não basta que somente a pessoa seja forte o suficiente para agüentar pressões. Um elástico, mesmo sendo flexível, sob pressões inadequadas demora, mas um dia se rompe ou não retorna mais ao estado original. É também tarefa das organizações, criar condições para que seus funcionários sintam-se bem onde estão trabalhando e, além disso, sintam-se úteis e capazes.

Koshiro Otani (2007, p.3) orienta que,

É preciso que os funcionários estejam felizes no desempenho de suas funções. A felicidade é diretamente proporcional ao respeito que a empresa dedica à dignidade dos seus colaboradores. Em outras palavras, organizações que em sua essência, desconsideram a dignidade dos seus funcionários, jamais terão pessoas resilientes em seu quadro.

Esta premissa também se aplica a alunos. Não ajudaremos a formar alunos resilientes se estes não forem respeitados, não tiverem a oportunidade de errar e alguém a lhes dizer que errar é normal e, que é uma forma de aprendizagem. Se não forem olhados como sujeitos em processo de formação de caráter e identidade, à medida que se desenvolvem e amadurecem, a formação resiliente não se concretizará.

Segundo o autor,

Trabalhar no sentido de criar um ambiente agradável e livre de tensões na sala de aula. $\mathrm{O}$ aluno precisa aprender a ser feliz na escola, descobrir o prazer de aprender e de fazer as suas atividades bem-feitas, aprender que é permitido errar e que o erro nos faz crescer. Não ter medo de descobrir, assumir e desenvolver a própria potencialidade. (BOMTEMPO, 1997, p.9). 
O aluno que não se sente acolhido pelo professor tende a desenvolver antipatia por este e, conseqüentemente, não conseguirá lidar com as dificuldades porque não encontra apoio. Diante disto muitos desistem no meio do caminho.

A afetividade é primordial para um bom equilíbrio mental, desenvolvendo a competência de aprender com as dificuldades e superá-las. Desta forma também contribui-se para o desenvolvimento da resiliência.

Evitar elogios, ver sempre o lado dos defeitos do outro, principalmente se estes são crianças ou adolescentes, utilizando rotulações do tipo: inquieto, danado, perturbador, desatento, tende a desenvolver nas pessoas um sentimento negativo de incompetência e insegurança, baixando a auto-estima, sentimento que inevitavelmente levará para a sua vida produtiva e de relacionamentos. Crianças que passam por estas situações possivelmente terão dificuldade em saber lidar com uma tragédia em sua vida. Poderá ser um sujeito não resiliente, já que isto não foi desenvolvido desde pequeno, pelo contrário, não teve alguém que pudesse ajudá-lo, e olhar para suas dificuldades e traquinagens como um pedido de ajuda ou carência afetiva.

Outra situação difícil para as crianças é saberem lidar com os apelidos por serem gordas, baixinhas, lentas, dentuças. São situações que poderão atingi-la profundamente tendo reflexos na sua aprendizagem, já que sua auto-estima tenderá a baixar. Devem os educadores estarem atentos para as situações que incomodam a criança e desenvolverem algum tipo de projeto que assuma o objetivo de promover a boa convivência e o respeito as diferenças.

Segundo o professor Haim Grunspum (2006) a resiliência pode ser desenvolvida e aquele que ajuda a desenvolvê-la é chamado de promovedor de resiliência. Pessoas que passam por catástrofes em conjunto ou sozinhos e recebem ajuda de promovedores poderão adquirir resiliência como foi o caso da tragédia da derrubada das torres em Nova York onde as famílias, filhos, vizinhos passaram por uma promoção de resiliência tendo um grande sucesso. Um promovedor seria portanto, uma pessoa que consegue identificar que uma criança é hiperativa, possui dislexia ou déficit de atenção, e que se propõe a ajudar seja ajudando em sala de aula da melhor forma possível, seja encaminhando para um especialista como um psicopedagogo.

Pais, professores, pedagogos, psicólogos ou médicos podem ser promovedores de resiliência, ajudando o sujeito a desenvolver autonomia, independência, novas alternativas para resolução de situações desafiantes, novas reflexões para suas atitudes, aprender a lidar com as frustrações, desenvolver a criatividade, aceitar e respeitar a si mesmo e aos outros. 
Muitas crianças, principalmente as pequenas, não conseguem falar sobre determinados assuntos dolorosos, somatizando e apresentando diversos sintomas desde queda de cabelos, dores de barriga, diarréia, constipação até amnésia parcial ou total, agressividade, que poderá refletir no baixo rendimento escolar.

É no contexto lúdico como o jogar, o brincar, o falar, o se expressar através de desenhos, pintura, modelagem, arte, dramatização, que se pode estar proporcionando à criança uma nova abordagem, uma reestruturação, uma re-elaboração, buscando o entendimento e a superação da situação conflitante provocando a melhora no rendimento escolar.

Em casa, os pais são imprescindíveis na ajuda à superação das dificuldades da criança. Dar afeto, compreensão, limites, dar oportunidades para desenvolver sua criatividade, oportunidades para se expressarem, auxiliar na sua autonomia, orientação religiosa, são ingredientes fundamentais para desenvolver resiliência. Estarão desta forma, promovendo resiliência em seus filhos preparando-os para no futuro saberem resolver problemas com bom equilíbrio emocional e saindo destes não deprimidos ou traumatizados, mas sim mais fortalecidos.

De acordo com Vicente (1998), a resiliência pode ser promovida através de três fatores: 1) Modelo de desafio - o sujeito consegue entender a dimensão do problema, o reconhecimento das possibilidades e enfrentamento, e o estabelecimento de metas para sua resolução; 2) Vínculos afetivos - aceitação incondicional do indivíduo enquanto pessoa, principalmente pela família; 3) Sentido de propósito no futuro - estabelecimento de metas, criação de objetivos, fé num futuro melhor.

Portanto, é essencial que se promova a resiliência no sujeito, ajudando-o a elevar sua auto-estima. Quando a pessoa se valoriza ela é capaz de resistir aos embates buscando um sentido de continuidade da vida, de superar com mais facilidade os acontecimentos ruins. Ela deseja melhorar, cuidar de si e do outro, traçar objetivos, transformando suas experiência negativas em novas aprendizagens para tornar-se alguém melhor seja no campo pessoal, social ou profissional.

Provavelmente todos nós já passamos por alguma situação em que proferimos a velha frase: nunca imaginei que isto fosse acontecer comigo. É neste momento em que decidimos o que fazer de nossas vidas, nos lamentarmos ou tomar esta dificuldade, aprender com ela e seguir em frente. 


\section{Referências}

BOMTEMPO, Luzia. Escola do coração. Um conjunto de atividades para desenvolver nos alunos a inteligência emocional. Amar Educando. Minas Gerais: Fundação Amae Educando, nº 268, jun., 1997.

GALIETA, I.C. Resiliência, o verdadeiro significado. 2004. Disponível em: <http://www.fae.edu/publicador/conteudo/foto/2082004isabel\%20camilo\%20galieta.pdf> Acesso em 16.06.2007.

GRUNSPUN, Haim. Criando filhos vitoriosos: quando e como promover a resiliência. São Paulo: Ateneu, 2006.

MONTEIRO, Denise Schulthais dos Anjos, PEREIRA, Luciana Fernades, SARMENTO, Marilza Rodrigues, AQUINO, Tânia Maura de. Resilência e Pedagogia da Presença: intervenção sócio-pedagógica no contexto escolar. In.: BELLO, José Luiz de Paiva. Pedagogia em Foco, Vitória, 2001. Disponível em: <http://www.pedagogiaemfoco.pro.br/ fundam01.htm>. Acesso em 20.06.2007.

OTANI, Koshiro. Resiliência. Disponível em <http://www.nippobrasil.com.br/2.semanal. saude/263.shtml > Acesso em 25.07.2007.

VICENTE, C. M. Promoção de resiliência. In: Políticas Públicas e Estratégias de Atendimento Socioeducativo ao Adolescente em Conflito com a Lei, Coleção Garantia de Direitos, Série Subsídios 2, pp. 67-72, Brasília: Departamento da Criança e do Adolescente, Ministério da Justiça, 1998.

\section{Sobre os autores:}

(1) Lívia Arcanjo Fonteles é graduada em Medicina pela Universidade Federal do Ceará. E-mail: liviaarcanjo84@hotmail.com

(1) Victor Emídio Campos é Educador e Mestrando em Ciências da Educação pela Universidad San Carlos - Paraguai.

E-mail: victoraltha@hotmail.com

\section{Como citar este artigo (Formato ISO):}

FONTELES, L.A. e CAMPOS, V.E.. Resiliência como recurso para a saúde emocional. Id on Line Revista de Psicologia, Novembro de 2010, vol., no.12, p.16-20. ISSN 1981-1189. 